\title{
Article
}

\section{Towards Principled Responsible Research and Innovation: Employing the Difference Principle in Funding Decisions}

Schroeder, Doris and Ladikas, Miltos

Available at http://clok.uclan.ac.uk/12757/

Schroeder, Doris ORCID: 0000-0002-3633-2758 and Ladikas, Miltos ORCID: 0000-0001-7958-8975 (2015) Towards Principled Responsible Research and Innovation: Employing the Difference Principle in Funding Decisions. Journal of Responsible Innovation, 2 (2). pp. 169-183. ISSN 2329-9460

It is advisable to refer to the publisher's version if you intend to cite from the work. http://dx.doi.org/10.1080/23299460.2015.1057798

For more information about UCLan's research in this area go to http://www.uclan.ac.uk/researchgroups/ and search for <name of research Group>.

For information about Research generally at UCLan please go to http://www.uclan.ac.uk/research/

All outputs in CLoK are protected by Intellectual Property Rights law, including Copyright law. Copyright, IPR and Moral Rights for the works on this site are retained by the individual authors and/or other copyright owners. Terms and conditions for use of this material are defined in the policies page.

\section{CLoK}

Central Lancashire online Knowledge www.clok.uclan.ac.uk

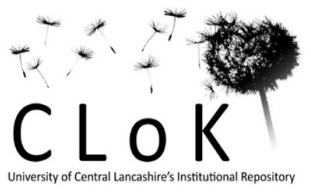




\title{
Towards Principled Responsible Research and Innovation: Employing the Difference Principle in Funding Decisions
}

\section{Author 1}

Prof. Doris Schroeder

dschroeder@uclan.ac.uk

\author{
Director - Centre for Professional Ethics \\ UCLAN School of Health \\ Brook 230, Preston \\ PR1 2HE, England \\ Tel. ++44 (0) 1772892550 \\ www.uclan.ac.uk/cpe \\ School of Law - Uclan Cyprus \\ dschroeder@uclancyprus.ac.cy \\ Centre for Applied Philosophy \\ And Public Ethics (CAPPE) \\ CSU, Canberra, Australia \\ dschroeder@csu.edu.au \\ Co-ordinator of FP7 RRI Project Progress - progressproject.eu/
}

\section{Author 2}

Dr Miltos Ladikas

miltos.ladikas@kit.edu

Scientific staff

Research area Innovation processes and impacts of technology

Phone: +49 3050365798

Institut für Technikfolgenabschätzung und Systemanalyse (ITAS)

Postfach 3640

76021 Karlsruhe

Germany

\section{Acknowledgements}

This article was written with support from the European Community's Seventh Framework Programme grant number 321400. Thanks also to helpful comments from delegates of the RRI Unbound Conference at Twente University; the University of Melbourne CAPPE Research Seminar; Julie Cook Lucas, Armin Schmidt; Roger Chennells, and four anonymous referees. 


\title{
Towards Principled Responsible Research and Innovation: Employing the Difference Principle in Funding Decisions
}

\begin{abstract}
There are reasons why the world's combined innovative capacity has spewed forth iPhones and space shuttles but not yet managed to produce clean energy or universal access to clean water.

Jack Stilgoe $(2013$, xii)

I derive great optimism from empathy's evolutionary antiquity. It makes it a robust trait that will develop in virtually every human being so that society can count on it and try to foster and grow it. It is a human universal. Frans de Vaal $(2009,209)$
\end{abstract}

Responsible Research and Innovation (RRI) has emerged as a science policy framework that attempts to import broad social values into technological innovation processes whilst supporting institutional decision-making under conditions of uncertainty and ambiguity. In this respect, RRI re-focuses technological governance from standard debates on risks to discussions about the ethical stewardship of innovation.

This is a radical step in Science \& Technology (S\&T) policy as it lifts the non-quantifiable concept of values into the driving seat of decision making. The focus of innovation then goes beyond product considerations to include the processes and - importantly - the purposes of innovation (Owen et al 2013: 34). Shared public values are seen as the cornerstone of the new RRI framework, while market mechanisms and risk-based regulations are of a secondary order.

What are the values that could drive RRI? There are different approaches to the identification of public values. They can be located in democratically agreed processes and commitments (such as European Union treaties and policy statements) or they can be developed organically via public engagement processes. Both approaches have advantages and disadvantages. For instance, although constitutional values can be regarded as democratically legitimate, their application to specific technological fields can be difficult or ambiguous (Schroeder and Rerimassie, 2015). On the other hand, public engagement can accurately reflect stakeholder values but is not necessarily free from bias and lobbyist agenda setting.

We argue that if RRI is to be more successful in resolving policy dilemmas arising from poorly described and uncertain technological impacts, basic universal principles need to be evoked and applied.

When looking at RRI from a 'principled' perspective, we consider responsibility and justice to be important cornerstones of the framework. One could describe them in the following manner: 
1. Research and innovation should be conducted responsibly.

2. Publicly funded research and innovation should be focused fairly on socially beneficial targets.

3. Research and Innovation should promote and not hinder social justice.

The main aim of this article is to suggest a method of realising these principles through the application of a limited Rawlsian Difference Principle in the distribution of public funds for research and innovation.

The paper is in three parts. The first part discusses the above principles and introduces the Rawlsian Difference principle. The second part identifies how RRI is currently applied by public funding bodies. The third part discusses the operationalisation of the Rawlsian Difference Principle in responsible funding decisions.

\section{Context and Justifying the Principles}

Research and innovation should be conducted responsibly

As Owen et al (2013: 27) have noted:

Few would disagree that science and innovation should be undertaken responsibly. "Responsible innovation" intuitively feels right in sentiment, as an ideal or aspiration.

However, what does this mean? How does one conduct research and innovation responsibly? In Europe, there is as yet no consensus on the definition of RRI. For this paper, we have chosen one prominent definition, namely:

a transparent, interactive process by which societal actors and innovators become mutually responsive to each other with a view to the (ethical) acceptability, sustainability and societal desirability of the innovation process and its marketable products (von Schomberg 2013: 63).

This definition locates the essence of RRI in research and innovation that is:

o ethically acceptable,

0 sustainable by realising intergenerational equity ${ }^{1}$ and

o driving towards the common good, i.e. aiming for societal desirability.

Ethical acceptability has been debated for decades, and principles as well as measures to attain it are converging globally. For instance, the Singapore Statement on Research Integrity ${ }^{2}$ 'is an important step toward promoting ethical conduct among scientists around

1 We are using an interpretation of von Schomberg's sustainability principle that was developed by Coles et al (2014a).

2 The principles and responsibilities set out in the 2010 Singapore Statement on Research Integrity represent the first international effort to encourage the development of unified policies, guidelines and codes of conduct, with the long-range goal of fostering greater integrity in research worldwide. The 
the world', maintaining, 'that there are some common standards ... that transcend national boundaries' (Resnik and Shamoo 2011: 71). More established statements of principles to achieve ethical acceptability include, for instance, the Declaration of Helsinki (World Medical Association 2013).

Risk management to ensure intergenerational equity, various forms of Technology Assessment (TA), and Foresight focusing on sustainability in Research \& Innovation (RI) have also seen significant funding and activity in recent decades with parliamentary TA offices now active throughout Europe. These represent similar processes of analysing S\&T developments, usually with a prominent social science perspective and an established methodological toolbox ranging from expert-only to public-engagement multi-disciplinary activities (Decker \& Ladikas, 2004). Without a principled make-over, RRI would be hardly different from TA/Foresight in terms of its tools and concepts, despite its much wider ambitions to incorporate broad social values into decision-making.

Of course there are voices against the use of any "principles" in science policy making (Holbrook \& Briggle, 2004). The argument is that principles are little more than a front for political intervention that stifles innovation and suppresses autonomy (interestingly, another fundamental principle). Despite the fact that some principles, recently introduced into decision making (e.g. the precautionary principle in food biotechnology), might appear to hinder innovation (compared to other regions, which do not apply such principles), this is far from a proof that principles hinder action. In the same way that a principled approach has been accepted in research involving human participants, animals and parts of the environment, avoiding exploitation and promoting beneficial research, principled RRI may capture the aspirations of society for fairness and justice. This does not mean politicising the decision making procedure but rather relocating it to the centre of societal priority setting. If justice is indeed a societal aspiration (as it appears to be from the central place it is given in constitutions all over the world) then it is a socially desirable goal that should permeate the decision making in every area of public interest. That includes science and innovation policy.

In contrast to issues around ethical acceptability and sustainability, achieving societal desirability has only recently emerged as a more forceful demand from science funders, national innovation policies and the public. More details will be given below, but a short illustration from the USA of the extreme approaches this concept can be used to serve can be found in Box 1.

\section{Box 1 - US Republicans on Societal Desirability}

The internationally respected US funding agency National Science Foundation (NSF) came under sustained attack in 2013 and 2014 by the Chair of the House Committee on Science, Space and Technology (Lamar Smith).

Statement is the product of the collective effort and insights of 340 individuals from 51 countries. These included researchers, funders, representatives of research institutions (universities and research institutes) and research publishers (http://www.singaporestatement.org/). 
Smith's mission - to show that the NSF allegedly wastes tax payers' money on 'frivolous or low-priority projects, particularly in the social sciences' - had led to an 'unprecedented-and some say bizarre-intrusion into the much admired process that NSF has used for more than 60 years to award research grants' (Shultz 2014).

Smith's staff had obtained access to NSF archives to unearth projects which were allegedly wasting tax payers' resources. The result were lists including the following:

- Bronze Age in Cyprus $\$ 197,127$

- Mayan architecture and the salt industry $\$ 233,141$

- Causes of stress in Bolivia $\$ 19,684$ (Cantor and Smith, 2013)

A journalistic effort by slate.com calculated that the projects selected by Smith Smith for major criticism only required $0.37 \%$ of the NSF budget and - included, 'a \$3 million grant awarded in 2008 to study how federal agencies can better communicate climate science to the public and a $\$ 5.6$ million award to a Columbia University team to carry out public education work on the impacts of climate change at the poles' (MacDonnell 2014).

Research on climate change education and communication clearly aims to drive towards the common good and therefore tax payers' benefit. Hence, Smith's criticism against a grant, which undertakes research on climate science communication is a good example of the ways in which societal desirability criteria can be used to further specific political agendas.

If one accepts a definition of RRI such at the one promoted by von Schomberg, Principle 1 (research and innovation should be conducted responsibly) would require respect for ethical precepts, the protection of resources as well as the health and safety interests of current and future generations, and an effort to use RRI to drive towards the common good.

Whilst the above may be acceptable to many in theory, contention arises when such principles are to be operationalised. To demand that researchers' and innovators' efforts drive towards the common good is likely to be the main point of contention, even if restricted to publicly funded efforts. As Michael Polanyi famously put it in The Republic of Science (Polanyi 1962): 'I appreciate the generous sentiments which actuate the aspiration of guiding the progress of science into socially beneficent channels, but I hold its aim to be impossible and indeed nonsensical.'

Although it is not clear how much 'direction' in science funding decisions is desirable, or even manageable, there are successful examples of efforts to guide national science and innovation policies, including funding policies, into socially beneficial channels that have been agreed through widespread public and political debates:

'Germany is a worldwide leader in almost all sectors of environmental technology... In 2030, Germany is projected to generate revenues of $€ 1$ billion in the 
environmental technologies industry' (Federal Ministry for Economic Affairs and Energy, undated).

It is no coincidence that the German Green Party is also one of the first green parties worldwide to enter a national parliament (in 1983) and that Germany was the only high income country which agreed a strategic plan for nuclear power phase out after Fukushima. Incentives provided through policy and funding can work, and research and innovation can be guided into socially beneficent channels. However, how to do so is certainly a difficult and valid question, which we will return to later.

Publicly funded research and innovation should be focused fairly on socially beneficial targets

Lamar Smith makes a good point when he states that whether tax payers' money is spent appropriately or not is an important topic. Both the government and tax payers have obligations as part of their roles within states: 'Social resources must be released to the government so that it can provide for the public goods' (Rawls, 1999: 246 - our emphasis). Just as citizens able to contribute taxes are under a duty of fair play, so are governments in receipt of tax payers' money: 'The tax dodger... violates the duty of fair play [as] he accepts the benefits of governments but will not do his part in releasing resources to it' (Rawls, 1997: 193). By implication, under conditions of fair exchange, governments need to do their part by providing for the public good, which we equate - in the context of this paper - with focusing publicly funded research and innovation on socially beneficial targets. Whilst this principle is broadly non-contentious (minus political anarchists or strict libertarians), its operationalisation is complex. The following table gives a simplified overview of some of the main problems in spending public funds for the public good.

Table 1: Some Obstacles to Focusing Publicly Funded Research and Innovation on Socially Beneficial Targets

\begin{tabular}{|c|c|c|}
\hline & Problem & Examples \\
\hline 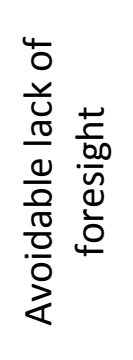 & $\begin{array}{l}\text { Whilst more and more methods exist } \\
\text { to involve the public in designing } \\
\text { desirable futures e.g. constructive TA } \\
\text { (Schot and Rip 1996), or real-time TA } \\
\text { (Guston and Sarewitz 2002), such } \\
\text { efforts cannot always be realised } \\
\text { successfully. }\end{array}$ & $\begin{array}{l}\text { In } 2010 \text {, the Netherlands put on hold a } \\
\text { new system of national Electronic Health } \\
\text { Records after serious concerns about } \\
\text { data protection were raised by civil } \\
\text { society groups. In } 2008 \text { alone, the wasted } \\
\text { expenditure was } 100 \text { million Euros (Smit } \\
\text { 2010). }\end{array}$ \\
\hline
\end{tabular}




\begin{tabular}{|c|c|c|}
\hline 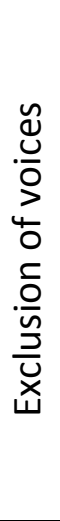 & $\begin{array}{l}\text { Focusing innovation on socially } \\
\text { beneficial targets requires a pluralistic } \\
\text { input that in turn assumes } \\
\text { widespread access to policy } \\
\text { structures. In reality only few } \\
\text { organised groups have such access. }\end{array}$ & $\begin{array}{l}\text { Over 4,500 lobbyists are active in the } \\
\text { European Parliament; } 72 \% \text { of } \\
\text { Parliamentary Members meet lobbyists at } \\
\text { least once a month and receive more } \\
\text { often voting instructions by interest } \\
\text { groups than their national governments } \\
\text { (Karapiperis and Ladikas, 2004). Lobbying } \\
\text { mobilises significant resources too: } \$ 3.5 \\
\text { billion was disclosed for lobbying the US } \\
\text { federal government in 2009(Alter 2010). }\end{array}$ \\
\hline 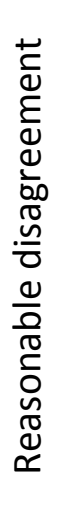 & $\begin{array}{l}\text { Even widespread consultation cannot } \\
\text { always guarantee agreement on social } \\
\text { ends given the different perceptions } \\
\text { of the human good. }\end{array}$ & $\begin{array}{l}\text { In autumn } 2013 \text { a joint statement of the } \\
\text { public health associations of Europe (IEA, } \\
\text { ISEE, EUPHA) was issued to call for a } \\
\text { major revision of the Horizon } 2020 \text { Work } \\
\text { Programme, which allegedly biases } \\
\text { research funding towards personalised } \\
\text { medicine to the detriment of public } \\
\text { health (Eupha 2013). The Work } \\
\text { Programme had been agreed after } \\
\text { extensive consultations. }\end{array}$ \\
\hline
\end{tabular}

The problems listed in the above table are serious. Whilst nobody is likely to vote or lobby for irresponsible RI or the squandering of public resources, RRI with a strong drive towards the common good may be abandoned as too idealistic to operationalise.

Research and Innovation should promote and not hinder social justice

'The term justice is now predominantly used in the moral assessment of social rules (laws, practices, social conventions and institutions) and only rarely in the moral assessment of the conduct and character of individual and collective agents' (Follesdal and Pogge 2005, 4). Many political philosophers have tried to capture what makes certain laws, practices, social conventions and institutions unjust, but again, agreement is not easily achieved. However, through the shift towards the justice of institutional arrangements rather than individual conduct, agreement can often be obtained on the fact that 'legal guarantees do not erode agency: They create a framework within which people can develop and exercise agency' (Nussbaum 1999, 19). Legal guarantees do not have to be binding laws. For instance, many ethics guidelines count as customary international law, given that they are being consistently applied and widely accepted as a practice (Brownlie 2003, 7). In this regard, RRI could develop into a framework within which people can develop and exercise agency, specialised on the topic of the governance of RI.

The attempt to import broad social values into technological innovation processes whilst supporting institutional decision-making under conditions of uncertainty and ambiguity, is likely to lead to many disagreements, which could be mitigated, we maintain, through reference to very basic values. 'Western philosophers generally regard justice as the most fundamental of all virtues for ... establishing and maintaining a stable political society' 
(Pomerleau 2013). As RRI frameworks are a subset of stable political societies, we suggest importing justice into the RRI framework.

The principle that 'RI should promote and not hinder social justice' is one of the easier justice principles to justify. It is a way of summarising the position that legal systems and instruments should be built in such a way that the exploitation or discrimination of the less fortunate is minimized, whilst assistance is provided where needed. If one goes back to individual conduct as the foundation of justice discussions, all major religions advocate the principle of non-exploitation and assistance for the needy (Lanczkowski 1989; von Glasenapp 1996; Weitz 2011). It has also been shown that solidarity based on empathy can be supported with evolutionary evidence. Renowned primatologist Frans de Waal argued in his book The Age of Empathy that 'greed is out, empathy is in' (2009, ix) and that, 'empathy engages brain areas that are more than a hundred million years old' $(2009,208)$.

\section{The Difference Principle}

Before reproducing generations of theories of justice in order to find a way of operationalizing justice within RRI frameworks ${ }^{3}$, we suggest using a well established, very specific justice principle which has gained considerable interest outside of philosophy. The originator of the principle is most highly regarded, as poignantly captured by Jonathan Wolff (Gordon 2008) who wrote:

While there might be a dispute about the second most important political philosopher of the 20th century, there could be no dispute about the most important: John Rawls.

The principle we are interested to import into RRI is part of John Rawls' Theory of Justice (Rawls, 1999). It is usually called the Difference Principle, or occasionally the Maximin principle. It has been designed for the moral assessment of social rules, in particular institutions and social systems. According to Philippe van Parijs (2003: 200),

[f]ew components of John Rawls's political philosophy have proven so epoch-making as what he somewhat oddly called the "difference principle". None has exercised as great an influence outside the circle of academic philosophers.

Those interested in the principle outside of academic philosophy are mostly economists. In economics, a tension exists between efficiency and equity. Simplified, laissez-faire capitalism favours efficiency, whilst movements from welfarism to communism favour equity (expressed, for instance, as basic need satisfaction or equality). The beauty of Rawls' Difference Principle is that he tries to marry the two: efficiency with equity. The idea is simple: given that efforts to achieve full equality will invariably lead to systematic and chronic inefficiencies, some inequalities will be allowed, but only if they lead to advantages for the least well off.

\footnotetext{
${ }^{3}$ For a useful overview of the relevance of justice criteria to science policy, see Cozzens 2007.
} 
The Difference Principle would therefore allow, say higher salaries for company directors, if they lead to sustainable livelihoods and meaningful occupations for some defined others. ${ }^{4}$ In Rawls' words:

The higher expectations of those better situated are just if and only if they work as part of a scheme which improves the expectations of the least advantaged members of society (Rawls 1999: 65).

The innovative idea is therefore that 'social and economic inequalities should be evaluated in terms of how well off they leave the worst off' (van Parijs, 2003: 200). This idea is appealing because it:

provides a transparent and elegant way of articulating an egalitarian impulse and a concern for efficiency. For it avoids, at the same time, the absurdity of equality at any price and the outrageousness of maximising the aggregate no matter how distributed (van Parijs, 2003: 200, emphasis added).

Like the Difference Principle, RRI is also concerned with efficiency and equity. For instance, increasing the acceptance of new products and technologies by end-users is one of the specific goals of societal engagement, which in turn is one of the tools of RRI. This is a move towards more economic efficiency, as it tries to prevent significant waste of resources, be they public or private (i.e. tax payers' money or industry investment). With regard to equity, and assuming an ideal scenario, societal engagement provides a platform for all to influence the world they would like to live in (e.g. does this world provide maximal scientific progress through unhampered access to personal medical data, or does it maximise the privacy of patients or is there any compromise between the two?).

Whilst the above concludes the concise summary of the Difference Principle, one further element from Rawls' Theory of Justice needs to be introduced, as it is directly relevant to our application example below. The Difference Principle aims to distribute something differently from its laisser-faire distribution. But what is it? To use technical terms that philosophers or economists might use: it is not utility, welfare or degree of preference satisfaction that is the target of the Difference Principle (van Parijs, 2003: 210). Hence, it is not wealth, unemployment insurance or anything that people want to be redistributed as a matter of personal taste. Rather Rawls' Difference Principle applies to a subset of primary goods. Primary goods are 'what persons need in their status as free and equal citizens, and as normal and fully cooperating members of society over a complete life' (Rawls, 1991: xiii). Rawls distinguishes between natural and social primary goods. Natural primary goods are, for instance, intelligence, imagination, vigour and health. Social primary goods are rights, liberties, opportunities, income and wealth (Rawls, 1991: 54). Access to the fruits of science and innovation therefore belongs to the social primary goods.

\footnotetext{
${ }^{4}$ Rawls does prohibit excessive inequalities in return for meagre benefits to the least advantaged. He says: "A scheme is unjust when the higher expectations ... are excessive" (1991: 68). Expectations in this context are the same as prospects or wealth and opportunities to be achieved through a particular societal set-up. As this limitation is not relevant to the case that we shall apply the principle to (the distribution of research funds, all other things being equal, see below), we are not going to provide details on this limiting scenario.
} 
Having understood both the scope and the content of the Difference Principle, our third part will give an example of how the principle could be operationalized (in a limited way) as part of efforts to achieve RRI. With this application of the principle, we would aim to redistribute, to the benefit of the least advantaged, the opportunities (social primary good) that derive from science and innovation, without compromising scientific efficiency. However, doing so without a movement that points in this direction could be called socially naive, simply suggesting a nice idea with no or at best limited potential for application. To show that this is not the case, we need to introduce what we call the 'impact movement' first, to show that our suggestion has been developed within the social context.

\section{The Application of RRI in Public Research Funding}

Traditionally, the scientific reward system is focused solely on scientific communities and within those, on scientific excellence. A new order emerging recently is characterised by a combination of both scientific excellence and societal impact as award criteria for science funding. Science is expected to account for its actions, both in the quality and in the relevance of its output for society. This necessitates a knowledge production process that is more open, transparent, inclusive, and responsible. Societal impact is the new 'holy grail' of research programmes whereby scientists must be able to present a narrative that explains the relevance and added value of their work for society. There is a shift in paradigm from the dominance of output parameters and performance indicators to openness, inclusiveness, reflexivity and other properties of RRI that are not easily captured in measurable indicators.

The terminology used in this context is varied and includes 'societal needs' as part of RRI (European Commission); 'broader impacts' (National Science Foundation (NSF), United States of America); 'responsible innovation' (Netherlands Organisation for Scientific Research (NOW)); 'impact' (Research Excellence Framework (REF), UK); 'science for accelerated development' (China $12^{\text {th }}$ Five-Year Plan), and 'bench to bedside' or 'translational medicine' (Wellcome Trust), (Coles et al 2014). The following examples are indicative of this trend.

\section{Focus on Societal Needs in European Commission Research}

A recent report on RRI commissioned by the European Commission starts as follows:

It is the ambition of the European Union to ensure that research and innovative ideas can be turned into products and services that create jobs and prosperity, as well as help preserve the environment and meet the societal needs of Europe and the world. To achieve this, the European institutions, its Member States and private business actors invest considerable monetary and human resources into Research, Development and Innovation. The need to gear the innovation process to societal needs is reflected in many high-level policy, strategy and programming documents, such as the objective of the EU 2020 strategy to create smart growth or the Horizon 2020 programme that defines tackling societal challenges as one of the main priorities (van den Hoven et al. 2013, 11, our emphasis). 
The European Commission's efforts to guide research towards societal needs rests on two pillars: first, a call or theme-based funding system, whereby most funds can only be obtained on topics pre-selected by the European Commission. These topics ideally align with societal challenges and needs as well as efforts to maintain world-leading competitiveness. Such efforts are, for instance, expressed in Europe 2020, the European Union's key strategy for the current decade, which aims to foster a smart, sustainable and inclusive economy. It says: 'innovation has been placed at the heart of the strategy', as it provides the 'best means of successfully tackling major societal challenges' (European Commission 2010, 2). The second pillar is an impact requirement for all funding applications, which accounts for one third of the evaluation marks (the other two thirds being scientific excellence and feasibility).

\section{Social Impact in the UK Research Excellence Framework (REF)}

Funding for academic research in the UK comes from two main sources: the research councils and the government's research evaluations. The current governmental evaluation model is called Research Excellence Framework (REF). It assesses research in the period from 2008 to 2014 and is very clear on its impact demands.

Within the REF, 'impact is defined as an effect on, change or benefit to the economy, society, culture, public policy or services, health, the environment or quality of life, beyond academia' (REF 2011: 26, our emphasis). Notably, the REF excludes effects within academia from impact. It says in the relevant documentation: 'impacts on research or the advancement of academic knowledge within the higher education sector (whether in the UK or internationally) are excluded' (REF 2011: 26) from the assessment of impact. Hence, what used to be the benchmarks for research success, the number of citations of journal articles (aptly called 'impact factor') does not satisfy the impact criterion under the REF. These outputs are captured elsewhere in the REF assessment.

\section{Responsible Innovation in the Netherlands Organisation for Scientific Research (NWO)}

Possibly the most ambitious program within the global impact movement is the Dutch 'Responsible Innovation' program (Maatschappelijk Verantwoord Innoveren (MVI)). It was launched by the Netherlands Organisation for Scientific Research in June 2008 and exemplifies the following rationale.

Technological developments may fail if their ethical and social consequences are not considered in time. Examples of this are the electronic patient file ${ }^{5}$... or the 'smart electric meter' 6 . The Responsible Innovation programme funds and encourages research that considers the ethical and social aspects of new technology from the design phase onwards. Researchers from different scientific disciplines - such as ethicists, behavioural scientists, economists and psychologists - collaborate in this programme.

The MVI (2014) enforces the following criteria:

See Table 1.

Smart electricity metres were to be installed widely as part of a Dutch energy reduction plan, but after serious privacy concerns were raised by civil society organisations, the installation is currently voluntary. 
o Adherence to pre-defined topics. For instance, the 2014 topics included, 'Production and growing methods aimed at a healthy living environment, food safety and food security', 'Assessment models in the transition to a more sustainable energy supply', or 'Smart cities and continued urbanisation'.

o Necessity to involve researchers from the humanities, the social sciences and the sciences/engineering in each proposal.

o Setting up of a valorisation panel, prior to submission. The panel consists of users or prospective users who will accompany the research from inception to completion.

o At least $25 \%$ of the overall funds must be matched by private partners, of which at least half must be in cash.

This is probably the most demanding research funding program in terms of impact requirements world-wide.

\section{An Example of a Principled Approach: Translational Research}

Whilst the above efforts are ongoing in a non-coordinated manner with funders developing their impact criteria in isolation from others, there is a global debate on the topic that attempts to operationalise impact on a clear principle, namely 'translational research'.

Translational research (sometime also found as translational medicine) is defined as follows:

Translational research is now a critically important current in academic medicine. Researchers in all health-related fields are being encouraged not only to demonstrate the potential benefits of their research but also to help identify the steps through which their research might be 'made practical' (Cribb 2010, 207).

The aim of translational research in medicine is to move from basic research - the bench - to medical practice - the bedside - more quickly and more efficiently than ever before (Ledford 2011). Publicly funded researchers in medicine are then not only required to show that there could be applications from their findings that are relevant to patients, but also how to ensure that these applications materialise. Those who develop the scientific background to something are made partly responsible for its successful translation into a real-life application. This approach is therefore highly demanding of researchers in requiring that their work must help specified people now or soon rather than an indeterminate group later. And, most importantly, that they have to push for this aim themselves.

The NIH in the US is one of the earliest funders making this demand strongly:

The National Institutes of Health $(\mathrm{NIH})$ has made translational research a priority, forming centers of translational research at its institutes and launching the Clinical and Translational Science Award (CTSA) program in 2006. With 24 CTSA-funded academic centers already established, other universities are transforming themselves to compete for upcoming CTSA grants. By 2012, the NIH expects to fund 60 such centers with a budget of $\$ 500$ million per year (Woolf 2008, 211). 
Likewise the demand for translational research was part of the European Commission's $€ 6$ billion budget for health-related research in the framework program that ended in $2013^{7}$ (Woolf 2008, 211). The world's second largest independent medical charity funding research, the Wellcome Trust also uses translation demands for those requesting funding. Its vision is 'to achieve extraordinary improvements in human and animal health. In pursuit of this, we support the brightest minds in biomedical research and the medical humanities.' (Wellcome Trust: undated). Hence, their mission now requires significant ('extraordinary') impact on human and animal health.

Thus, demands for translational research are growing and they are even more demanding than impact requirements since they make the researchers themselves responsible for translating their research into something tangible for, in most cases, human well-being. How does our attempt to create a principled RRI through the import of justice relate to the global impact and translational research movement?

\section{Importing Justice into RRI}

Achieving societal desirability as part of RRI is plagued with problems, including avoidable and epistemic lack of foresight, exclusion of voices, and reasonable disagreements, as summarized above. On the other hand, public funders' efforts to achieve beneficial impact on society through research funding are on the increase and are irreversible. Societal impact is here to stay in all major future research programme evaluation and it is imperative to fill the conceptual gaps in its application with established principles such as the principle of justice. Applying a limited funding criterion based on the principle of justice will strengthen the current efforts of research funders to promote RRI, and in particular societal desirability.

It has been argued that societal desirability decisions could be linked to constitutional values (Ozolina et al 2012). However, it is not clear how constitutional values could be operationalised to guide very specific funding decisions. It is perhaps possible to link decisions on funding to constitutional values at an abstract level (e.g. synthetic biology governance conditions need to respect the principle of sustainability with regard to health risks), however, such values seem to be too ambitious to facilitate everyday decisions as to which research proposal should be funded.

Others have suggested using the Grand Challenges (von Schomberg 2013, 51), as for instance formulated in the Lund Declaration, to drive innovation towards the common good and achieve societal desirability. 'The declaration establishes that the EU's research policy should abandon the present thematic and bureaucratic structure and focus instead on mustering its resources to solve some of the major challenges facing the world, for example the climate threat, water shortages, demography and pandemics' (Lund Declaration undated). In the context of our example though, we certainly do not want to argue that all research funding (in Europe) should be spent on climate change, ageing societies etc. In this regard, research funders would still need other criteria to achieve societal desirability at a level where constitutional values are too ambitious and Grand Challenges are too specific.

\footnotetext{
${ }^{7}$ At the time of writing, the funding situation for translational research in health under Horizon 2020 (20142020), the current EU funding program, is not yet clear.
} 
To move the debate on societal desirability and by implication on RRI forward, a new approach needs to be devised, which would be acceptable to researchers and innovators, RI funders and the general public. To repeat, whilst constitutional values should have the support of all of the above and a link of funding decisions to such values might therefore seem plausible, this approach is too ambitious for individual funding decisions. At the same time, whilst funding is urgently needed for the Grand Challenges, individual funding decisions will still have to be made outside of the thematic areas of climate change, ageing societies etc.

The Difference Principle is a good candidate for an operational funding criterion based on a fundamental value; that of justice. Recalling Rawls, a full Difference Principle would only allow the receipt of research funds if this receipt would also benefit the least advantaged more than alternative scenarios. 'The higher expectations of those better situated are just if and only if they work as part of a scheme which improves the expectations of the least advantaged members of society' (Rawls 1999: 65). Rather than such a radical demand to guide research funding towards benefitting the least fortunate, we suggest a limited Difference Principle: if two proposals scored equally on all criteria (e.g. scientific merit) and only one could be funded, the one that has the highest potential benefit for the least advantaged should be chosen. Thereby, a justice principle would inform RRI debates and decisions in a contentious area (societal desirability) and be operationalised through a principle which is highly respected amongst politicians and political philosophers alike.

It is important to note that the principle of justice is already strongly enshrined in most national guidelines and therefore conceptually accessible to most researchers. For instance, Articles 47 to 50 of the EU Charter (European Parliament 2001) deal with justice: they include the right to a fair trial, the right to be presumed innocent and the right to proportionate punishment. These rights may have no direct relevance to S\&T policy but they also do not employ the full scope of the justice principle. They focus on corrective and retributive justice whereas distributive justice could be especially relevant to RRI as described by Rawls above. It is therefore meaningful to recall the EU Charter when applying the Difference Principle, a step that both legitimises the choice and provides a strong connection between the aspirations of the EU and the application of its founding principles in S\&T.

At the same time, it is worth noting that Horizon 2020, the current EU research funding initiative, has already incorporated the principle of justice into its program in a very practical manner. Any applicant who envisages using resources from low and/or lower middle income countries (these include human research participants and data), must satisfy an EU ethics review panel that adequate benefit sharing measures (e.g. technology transfer, education, equitable input into project aims and deliverables) have been built into the proposal.

Even given the above, there are some obvious questions about the application of this scheme that need to be addressed, such as:

Least advantaged, where? If the funder were in the Netherlands, would the least advantaged be in the Netherlands? Rawls famously rejects the application of the Difference Principle on 
a global scale. Nevertheless, depending on the size and aims of the programme, both local and global levels of operationalisation are possible. For instance, a programme on new medical devices for cardiac operations should normally consider the Difference Principle at local/national level whereas a programme on Ebola/HIV vaccine development should consider the Difference Principle at the global scale. In other words, the criterion could be fully compatible, if used in the Rawlsian sense, with the current practices of research funders, as the normal scope of the relevant research programs could remain unchanged.

Who would decide which proposal would serve the least advantaged better out of any existing two ${ }^{8}$ There is a pragmatic answer to that question as well. Each funding agency could import the limited Difference Principle into their current funding guidelines and test how existing decision-making structures cope with an additional funding criterion. Obviously, applicants would have to be informed about the scope and application of the limited Difference Principle, making it fully transparent. For instance, research submissions to the European Commission are ranked by scientific experts and later examined by ethics experts on their ethical acceptability. There are ethical guidelines that help applicants to incorporate them in their research programme and reviewers to guide their decisions. Once incorporated in the guidelines, both groups of experts could be asked to apply the limited Difference Principle. Similarly, research submissions to the Dutch program on Responsible Innovation and the Wellcome Trust are reviewed by scientific experts and ranked by additional independent committees; both could apply the limited Difference Principle. The beauty of this approach is two-fold:

1) It would be within the grasp of researchers to fulfil the criterion through good planning of their research and at the same time, there is an institutional drive, which ensures societal benefits from research for the least advantaged.

2) Research ethics could be broadened with this approach to address criticism that it is overly thin with regard to respect for societal goals (Douglas 2014).

Woodhouse and Sarewitz (2007: 411) noted that "major changes in science-policy institutions ... would be required for R\&D to serve humanity equitably." Our suggestion does not require a major change in science-policy institutions ${ }^{9}$. However, it could represent a small step towards a fairer society, in which the distribution of RI public moneys is balanced in favour of the least advantaged without seriously endangering blue skies research or requiring societal desirability assessment of a subtlety and complexity that is not (yet) feasible, while at the same time strengthening the concept of RRI with a well-respected justice principle. Win-win. Win-win-win, if one adds that the incorporation of a justice principle into the RRI discourse could link the discourse to other, more established, discourses on human rights and corporate social responsibility. And this would bring RRI to the forefront of debates on social values and principles, a position that it aspires to achieve in society.

\footnotetext{
8 Of course, the limited Difference Principle could be used to rank proposals of any numbers.

${ }^{9}$ Research funding is a subset of science-policy institutions.
} 


\section{Bibliography}

Alter, Rolf. 2010. Clearer lobbying for cleaner policymaking. OECD Observer. Accessed October 252014.

http://www.oecdobserver.org/news/archivestory.php/aid/3254/\%20Clearer lobbyin $\mathrm{g}$ for cleaner policymaking.htm.

Brownlie, Ian. 2003 Principles of Public International Law. New York: Oxford University Press.

Cantor, Eric and Lamar Smith. 2013. "Eric Cantor and Lamar Smith: Rethinking science funding." 30 September 2013. Accessed December 282014.

http://www.usatoday.com/story/opinion/2013/09/30/cantor-gop-budget-sciencespending-column/2896333/.

Coles David, Davis M, Engelhard M, Han B, Kumar A, Laas K, Ladikas M, Lin R, Lingner S, Majima S, Pereira L, Rush E, Schrempf B, Schroeder D, Srinivas R, Walker M, Weckert J, Wynberg R, Zhizhong Y. 2014. Innovation for Society - Report for FP7 Project "Progress", progressproject.eu. Accessed January 82015. http://www.progressproject.eu/project-deliverables/.

Coles David, Engelhard M, Han B, Kumar A, Laas K, Ladikas M, Lin R, Schroeder D, Srinivas R, van Niekerk J, Walker M, Weckert J. 2014a. RRI Country Requirements Matrix Report for FP7 Project "Progress", progressproject.eu. Accessed April 292015. http://www.progressproject.eu/project-deliverables/.

Cozzens, Susan E. 2007. "Distributive Justice in Science and Technology Policy." Science and Public Policy 34:2, 85-94.

Cribb Alan. 2010. "Translational ethics? The theory-practice gap in medical ethics." Journal of Medical Ethics 36: 207-210

Decker, M. \& Ladikas, M. (2004, Eds) Bridges between Science, Society and Policy; Technology Assessment - Methods and Impacts (2004). Springer Verlag, Berlin

De Waal, Frans. 2009. The Age of Empathy. New York: Harmony Books.

Douglas, Heather. 2014. "The Moral Terrain of Science." Erkenntnis 79(5) Supplement: 961979.

Eupha. 2013. Joint statement of the public health associations of Europe (IEA, ISEE, EUPHA) on the health research programme 2014-2015 (Horizon2020) proposed by the European Commission. Accessed October 252014. http://www.eupha.org/repository/publications/joint statement IEA ISEE EUPHA 3 0 Sep 2013.pdf.

European Commission. 2010. Communication from the Commission to the European Parliament, the Council, the European Economic and Social Committee and the Committee of the Regions, Europe 2020 Flagship Initiative Innovation Union SEC(2010) 1161.

European Parliament. 2001. The Charter of Fundamental Rights of the European Union. Accessed October 252014 http://www.europarl.europa.eu/charter/default_en.htm

Federal Ministry for Economic Affairs and Energy (undated) Energy and environmental technology: Pioneer in Europe. Accessed December 272014 http://www.make-it-ingermany.com/en/for-qualified-professionals/working/industry-profiles/energy-andenvironmental-technology-pioneer-in-europe.

Follesdal, Andreas, and Thomas Pogge. 2005. "Introduction." In Real World Justice, edited by Andreas Follesdal and Thomas Pogge, 1-19, Berlin, Springer. 
Gordon, David. 2008. "Going off the Rawls." The American Conservative. Accessed January 8 2014. http://www.theamericanconservative.com/articles/going-off-the-rawls/.

Guston, David and Sarewitz Daniel. 2002. Real-time technology assessment. Technology in Society 24: 93-109.

Holbrook, J Britt and Briggle, Adam. 2004. Knowledge kills action - why principles should play a limited role in policy-making. Journal of Responsible Innovation, 1, 1: 51-66

Karapiperis, T. and Miltos Ladikas. 2004. "Organised Interests in S\&T Policy; The Influence of Lobby Activities". In Michael Decker and Miltos Ladikas (eds) Bridges between Science, Society and Policy; Technology Assessment - Methods and Impacts. Heidelberg, Germany: Springer.

Lanczkowski Guenter. 1989. Geschichte der nichtchristlichen Religionen. Frankfurt: Fischer Lund Declaration. Undated. Accessed October 252014.

http://www.vr.se/inenglish/aboutus/policies/lunddeclaration.4.44482f6612355bb5e e780003083.html.

MacDonnell, Tim. 2014. Taking Research for Granted - Texas Republican Lamar Smith continues his crusade against independence in science. 21 October 2014. Accessed December 282014.

http://www.slate.com/articles/health_and_science/climate_desk/2014/10/science_f unding_lamar_smith_continues_the_republican_crusade_against_research.html.

MVI. 2014. Calls for Proposals - Responsible Innovation. Accessed January 82015. http://www.nwo.nl/en/funding/our-funding-instruments/gw/responsibleinnovation/responsible-innovation.html.

Nussbaum, Martha. 1999. Sex and Social Justice. Oxford: Oxford University Press.

Ozolina, Zaneta, Carl Mitcham, Doris Schroeder, Emilio Mordini, Paul McCarthy and John Crowley. 2012. Ethical and Regulatory Challenges to Science and Research Policy at the Global Level, Expert Group report, Directorate-General for Research and Innovation of the European Commission. Luxembourg: Publication Office of the European Union.

Owen Richard, Jack Stilgoe, Phil Macnaghten, Mike Gorman, Erik Fisher, and Dave Guston. 2013. "A Framework for Responsible Innovation." In Responsible Innovation edited by Richard Owen, John Bessant, and Maggy Heintz, 27-50, London; John Wiley.

Parijs, Philippe van. 2003. "Difference Principles." In Cambridge Companion to John Rawls edited by Samuel Freeman, 200-240, Cambridge; Cambridge University Press.

Polanyi, Michael. 1962. "The Republic of Science: Its Political and Economic Theory". Accessed October 25.

http://sciencepolicy.colorado.edu/students/envs_5100/polanyi_1967.pdf

Pomerleau, Wayne. 2013. "Western Theories of Justice". Internet Encyclopedia of Philosophy. Accessed October 24. http://www.iep.utm.edu/justwest.

Rawls, John. 1997. "Justice as Fairness". In Contemporary Political Philosophy, edited by Robert Goodin and Philip Pettit. Oxford: Blackwell, pp.187-202.

Rawls, John. 1999. A Theory of Justice - Revised Edition. Oxford: Oxford University Press. REF. 2011. Assessment framework and guidance on submissions. Accessed October 24. http://www.ref.ac.uk/pubs/2011-02.

Resnik, David and Adil Shamoo. 2011. "The Singapore Statement on Research Integrity". Accountability in Research 18: 71-75. 
Schot, Johan and Arie Rip. 1996. "The past and future of constructive technology assessment" Technological Forecasting and Social Change 54: 251-268.

Schroeder, Doris and Virgil Rerimassie. 2015 forthcoming. "Science and Technology Governance and European Values" In Science and Technology Governance and Ethics edited by Miltos Ladikas et al, Berlin: Springer.

Shultz, David. 2014. "Science Insider - Breaking news and analysis from the world of science policy". 2 October 2014. Accessed December 28.

http://news.sciencemag.org/policy/2014/10/battle-between-nsf-and-house-sciencecommittee-escalates-how-did-it-get-bad.

Smit, Ton. 2010. "Dutch EHR plans put on hold." Ehealth INSIDER. Accessed October 24. http://www.ehi.co.uk/insight/analysis/608/dutch-ehr-plans-put-on-hold.

Stilgoe, Jack. 2013. "Foreword: Why Responsible Innovation?" In Responsible Innovation edited by Richard Owen, John Bessant, and Maggy Heintz, xi-xv, London; John Wiley.

van den Hoven, Jeroen, Klaus Jacob, Linda Nielsen, Françoise Roure, Laima Rudze, Jack Stilgoe. 2013. Options for Strengthening Responsible Research and Innovation, Directorate-General for Research and Innovation, Science in Society, Brussels.

von Glasenapp Helmuth. 1996. Die fuenf Weltreligionen. Muenchen, Eugen Diederichs Verlag.

von Schomberg, Rene. 2013. "A Vision of Responsible Research and Innovation." In Responsible Innovation edited by Richard Owen, John Bessant, and Maggy Heintz, 5174, London; John Wiley.

Weitz Burkhard. 2011. Nachgefragt: Weltreligionen. Berlin: Zentralen fuer Politische Bildung Wellcome Trust. Undated. Accessed October 24. Our Vision. http://www.wellcome.ac.uk/Our-vision/index.htm

Woodhouse, Edward, and Daniel Sarewitz. 2007. "Science Policies for Reducing Societal Inequities." Science and Public Policy, 34:3, 139-150.

Woolf, Steven. 2008. The Meaning of Translational Research and Why It Matters, JAMA 299(2): 211-213.

World Medical Association (2013) Declaration of Helsinki. Accessed October 25. http://www.wma.net/en/30publications/10policies/b3/, 